\title{
REPRESENTAÇÃO EM ROUSSEAU E HANNAH ARENDT
}

Maria Aparecida Azevedo Abreu

Tanto Hannah Arendt quanto Rousseau são críticos à representação política. Contudo, as formas com que cada um constrói sua crítica são bem distintas. Os dois podem ser considerados, sob muitos aspectos, "adversários" no terreno da teoria política, o que é explicitado por Arendt em $D a$ revolução.

O propósito deste texto é colocar em evidência os pontos de aproximação e afastamento entre os dois autores no que diz respeito à sua crítica à representação política. Obviamente, neste propósito, deverá ser percorrido um caminho por alguns conceitos centrais na obra de ambos.

\section{Representação: um problema para nossos autores}

Na obra de Rousseau, sua crítica à representação política, no sentido de escolha de mandatários, está associada à sua formulação do conceito de soberania. Para ele, a soberania deve ter como titular o conjunto de todos os cidadãos e não pode ser delegada nem dividida. Sem essa possibilidade, não há como haver representantes que decidam em nome dos cidadãos. Embora isto valha em relação ao legislativo, não vale em relação à composição do Governo, nome 
dado ao que chamaríamos hoje de Poder Executivo, que nada mais é do que "um corpo intermediário estabelecido entre os súditos e o soberano para sua mútua correspondência, encarregado da execução das leis e da manutenção da liberdade, tanto civil como política" (Rousseau, 1987a, p. 74). Isto ocorre porque este Governo de que fala Rousseau não detém o poder legislativo, este sim a própria manifestação da vontade geral e da soberania, que deve ser exercida diretamente pelo povo, sem o intermédio de quaisquer representantes. E, para Rousseau, não importa a dimensão da república em que esta soberania deva ser exercida: a autoridade soberana é simples e una, e não se pode dividi-la sem destruíla (Rousseau, 1987a, p. 105). Aqui, Rousseau é adversário de Montesquieu, atribuindo ao órgão executivo apenas funções administrativas sem dividir o poder soberano, que é o legislativo.

Hannah Arendt critica radicalmente a noção de sobe176 rania de Rousseau, filiando-se explicitamente à linhagem da divisão e da limitação dos poderes de Montesquieu e adotada pelos founding fathers norte-americanos. Sua crítica à representação política está associada à sua concepção de liberdade. Para ela, a liberdade emerge quando diversas pessoas agem em concerto. E essa liberdade ou significa "participar do governo" ou não significa nada (Arendt, 1988, p. 175). Embora não esclareça o que seja exatamente essa participação no governo, ela sugere uma estrutura de conselhos, pelo menos em sua origem espontâneos, que não tenham como finalidade nenhuma decisão burocrático-administrativa. A autora utiliza exemplos históricos para afirmar que nos conselhos devem estar presentes mais questões políticas do que sociais, o que significa que nos conselhos deveria haver manifestações de opiniões, mas não defesas de interesses particulares e, para Arendt, essas opiniões são indelegáveis: "a única coisa que pode ser objeto de representação ou de delegação é o interesse ou o bem-estar 
dos outorgantes, mas não suas ações ou opiniões" (Arendt, 1988, p. 175). Os conselhos deveriam ser locais em que as pessoas pudessem se manifestar e agir politicamente. A respeito de que e como seria essa ação são pontos que não ficam claros na obra da autora, mas o que ela afirma é que, com sua formação espontânea e com sua estruturação "de baixo para cima”, os que assumiriam posições de comando assim o fariam por sua idoneidade ou seu talento político. Esta estrutura, segundo Arendt, sobreviveu até que seus membros passaram a administrar e a comandar também as fábricas e, assim, os conselhos deixaram de ser o espaço para a manifestação de opiniões e ações genuinamente políticas e não sociais (Arendt, 1988). Com estas características, a crítica à representação política de Hannah Arendt tem como finalidade o afastamento da burocratização da política e a tentativa de construção e preservação de espaços em que uma ação política genuína possa acontecer.

Estes poderiam ser considerados os pontos centrais da crítica à representação política feita pelos dois autores. No entanto, Arendt e Rousseau divergem radicalmente no que diz respeito à representação, não no sentido de escolha de mandatários, mas de "aparecimento" no espaço público político. Para Arendt, a política é e deve ser representação. São freqüentes as comparações feitas pela autora da política com o teatro. Os atores políticos se comunicam e agem no cenário político revestidos de uma persona, que confere igualdade aos atores e, mais do que isso, os afasta de suas necessidades pessoais e de suas idiossincrasias. Com esta persona, os atores podem ser livres, realizando, portanto, o sentido da política, na visão da autora. A igualdade conferida pela persona compreende inclusive e principalmente a igualdade de direitos e precede a própria ação política. Em outras palavras, a igualdade conferida pela persona é condição para que seja realizada a ação política na concepção de Hannah Arendt. Ou seja, a mediação da representação é 
necessária para a constituição da igualdade, que por sua vez é um pré-requisito para a ação política.

Para Rousseau, representação é aquilo que temos a todo o tempo no que ele denomina sociedade civil, que é um grande alvo de críticas em toda a sua obra. Representação, para o autor, está relacionada com aparência, com velamento e, em algumas passagens, até mesmo com falsidade. Em contraposição a estas expressões, temos essência, verdade, autenticidade, sinceridade e transparência. Em outras palavras, enquanto para Arendt a representação na política não só não é negativa, como é algo que deve ser preservado, para Rousseau a representação deve ser afastada, e as pessoas devem buscar manifestar-se, em todos os campos, inclusive na política, de forma autêntica e transparente, o que significa dizer sem mediações.

Como se vê, temos aqui dois sentidos da palavra representação. Para Arendt, é justamente para garantir a representação, no sentido de aparecimento e revelação pública que se deve afastar a representação política. Para Rousseau, a representação política, quando aplicada ao poder legislativo, é mais uma forma de falseamento e de substituição do que é essencial pelo que é superficial que a representação, no outro sentido, possibilita. Ou seja, para o autor, os dois sentidos de representação se confundem, podendo a representação política ser praticamente uma espécie do primeiro.

Para Arendt, a defesa da representação como apresentação dos atores políticos está relacionada com a valorização que ela dá à igualdade estabelecida juridicamente e, portanto, de modo artificial. Para ela a igualdade é uma convenção necessária ao espaço político, para que possa haver a comunicação e a ação entre iguais. No espaço político, os atores se revestem de uma "máscara", sua persona, ou seja, os atores passam a ser não homens naturais, mas sujeitos de direitos e deveres e, portanto, protegidos por uma ordem jurídica. Ora, mas para Rousseau a constituição de um conjunto 
de leis que estabeleçam direitos e organize politicamente um conjunto de cidadãos também é de suma importância. Aliás, o seu contrato social é constituído juridicamente e constitui um elemento regulador e ordenador da comunidade de cidadãos. Mas em que estaria a diferença? Para responder a esta pergunta, temos de nos deter na concepção de natureza que cada um de nossos autores tinha como pano de fundo para suas reflexões.

\section{Natureza, artifício e convenção}

A noção de natureza é utilizada pelos nossos autores de forma distinta. Rousseau formulou o conceito de estado de natureza em oposição ao de sociedade civil e com isto filiou-se ao contratualismo. Hannah Arendt, em contrapartida, não se utiliza deste conceito, nem mesmo assenta sua teoria política na idéia de um contrato social. No entanto, em ambos os autores, há referência a algum estágio político não-convencional, ou não-artificial, que guarda características que se tornam referências - positivas, no caso de Rousseau, e negativas, no caso de Arendt - para a caracterização de que tipo de construção artificial da política cada um deles pretende. Natureza, portanto, para ambos os autores, ainda que em registros distintos, é sempre oposta a artifício e a convenção.

A formulação feita por Rousseau do "estado de natureza" é bastante conhecida, e vou retomá-la aqui para destacar que o estado de natureza é para Rousseau uma referência positiva destruída pela sociedade civil. Segundo o autor, caberia a um contrato social estabelecer convenções que limitassem e regulamentassem a vida social de forma a restituir o que fora perdido do estado de natureza, ou seja, restituir a igualdade que lá estava presente e que já não mais existe no que ele chama de sociedade civil. Esta sociedade civil é um mundo de aparências, de exploração de um homem por outro homem, da busca deste por ser o preferido pelos demais e, 
por isso mesmo, permeada por futilidades e superfluidades. É, portanto, um mundo de falseamentos, criado de forma artificial. Para desfazê-lo, ou afastar os seus efeitos, dos quais o mais contundente é a desigualdade instaurada pela apropriação de bens, é necessária a criação de uma outra sociedade, também de forma artificial, por meio do contrato. $\mathrm{O}$ contrato social é, pois, um artifício para desfazer outro artifício. É a sociedade moral do dever substituindo a sociedade imoral da desigualdade (Viroli, 1992).

Esquematizando de forma bastante resumida e simplificada, no estado de natureza tem-se uma igualdade natural, que é desfeita pela vida do homem em sociedade civil. Ou seja, a formação da sociedade - artificial, porque criada pelo homem - trouxe a desigualdade por meio do estabelecimento da propriedade, da busca por estima e da superfluidade. (Rousseau, 2005, pp. 210-211). Esta sociedade, embora artificial, pode ser considerada uma "continuação" do estado de natureza, que enfatiza não a igualdade dos homens, mas suas diferenças, e as transforma em desigualdades sociais (Viroli, 1992). Sem o estabelecimento de qualquer pacto que a ordene, esta sociedade civil pode ser vista como uma espécie de "desordem" derivada do estado de natureza. Neste sentido, a sociedade artificial trouxe efeitos negativos para a vida humana. Mas o fato de ser artificial significa também que ela pode ser modificada e - por que não? - transformada por meio de outro artifício, o Contrato Social.

Assim sendo, artifício, para Rousseau, tem um duplo significado: ao mesmo tempo em que trouxe as agruras da vida do homem em sociedade pode trazer o estabelecimento de uma sociedade moral, em que os homens estejam orientados pelo dever, ajam tendo em vista o bem comum e, para citar uma expressão já consagrada, estejam "obrigados a serem livres". O Contrato Social, com isto, poderá "ordenar" artificialmente a "desordem" artificial. 
O contrato social poderia ser visto como a "saída política" oferecida por Rousseau para os problemas apresentados pela sociedade civil. No entanto, há efeitos desta presentes em todas as esferas das relações humanas, que dizem respeito à valorização do luxo e das aparências. Para afastar essas características, Rousseau parece apontar em suas obras não propriamente políticas ser necessário, além do contrato social estabelecido por convenção, buscar a natureza das coisas, em todos os campos da vida. É nesse sentido que Rousseau desenvolve as suas reflexões sobre a educação de um cidadão em Emílio. Ali, percebe-se a busca pelas sensações e experiências mais autênticas, desde o momento da infância, para que só a partir delas possa se chegar à razão. Nesta educação, segundo o autor, está o antídoto contra o deslumbramento provocado pela vida em sociedade (é a francesa do século XVIII, a que o nosso autor se refere) e a garantia de que o cidadão daquela forma educado possa ser um cidadão sóbrio, com sólidos sentimentos de justiça e preparado para não somente pensar em seus interesses, mas também viver em comunidade. O projeto de educação de Rousseau pode ser visto como um projeto para levar o indivíduo à razão. Ora, o contrato social, obviamente, é um projeto de racionalidade, tanto no aspecto de cálculo, ou seja, de tornar as ações políticas previsíveis e inseridas num âmbito de moralidade, quanto no aspecto de justificação e de legitimação dessas mesmas ações (Viroli, 1992).

A busca das experiências originárias do indivíduo descritas em Emílio nos leva de volta ao estado de natureza. Este pode ser visto também como um estado de autenticidade e de sinceridade, em que a vida coletiva dos seres humanos acontece não por meio de mediações, mas por meio da comunicação sincera, transparente e espontânea entre eles. $\mathrm{O}$ anseio por transparência e sinceridade se encontra presente de forma explícita nos textos não propriamente políticos de Rousseau e, de uma certa forma, permeia toda 
sua obra (Starobinski, 1991). No âmbito político, a transparência na comunicação entre os agentes significa comunicação que não seja mediada por interesses particulares e neste aspecto Rousseau condena o luxo e a superficialidade e coloca reservas na importância do dinheiro em uma comunidade. Com uma noção de autonomia bastante forte, Rousseau propõe para uma comunidade política - Polônia, neste caso - que ela procure depender o menos possível do comércio internacional e que estimule, ao invés da riqueza, resultado do acúmulo de bens, a prosperidade, que significa cada vez mais ter os bens necessários e o desenvolvimento das virtudes do povo (Rousseau, 1982, p. 74). As idéias de espontaneidade e de desenvolvimento das virtudes parecem estar traduzidas na idéia de vontade geral, que pode ser vista como uma espécie de vontade comum, obtida espontaneamente por cidadãos movidos pelo bem de toda a comunidade. A espontaneidade necessária para a formação 182 da vontade comum, com a ausência de interesses e, portanto, de mediações, está fortemente relacionada com a transparência desejada por Rousseau. Assim sendo, o contrato social deveria calcar-se numa vontade comum espontânea, em que os indivíduos já não são mais indivíduos portadores de interesses, mas cidadãos agindo de forma transparente, sem mediações, tendo em vista o bem comum.

Espontaneidade e ausência de interesses também são exigências colocadas por Hannnah Arendt aos atores políticos. No entanto, a espontaneidade de que fala Arendt não envolve a noção de transparência, como se encontra presente em Rousseau. Arendt não só não postula a transparência, como a considera perniciosa para a política. Isto fica claro quando ela analisa o período do Terror na Revolução Francesa e a "caça aos hipócritas" ali ocorrida:

"Todo feito tem seus motivos, bem como seu objetivo e seu princípio; mas o próprio ato, embora proclame seu 
objetivo e torne manifesto seu princípio, não revela a motivação íntima do agente. Seus motivos permanecem obscuros, não aparecem, antes se escondem, não apenas dos outros, como também de si próprio e de sua autoanálise. [...] Na política, mais do que em qualquer outro campo, não temos possibilidade de distinguir entre o ser e a aparência. No mundo das relações humanas, o ser e a aparência são, de fato, uma só e a mesma coisa" (Arendt, 1988, pp. 77-78).

Esta passagem não é dirigida diretamente contra Rousseau como em outras passagens de Da revolução, mas poderia o ser. Para Arendt, como explicitado na citação acima, ser e aparência coincidem. Ora, nada mais oposto ao que Rousseau propunha. Para ele, com o avanço da sociedade civil, um dos efeitos dela decorrente é o distanciamento entre ser e aparência (Rousseau, 2005, p. 217). A aparência pode deformar aquilo que é, e as representações podem ser vistas como falsificações da realidade.

Para Arendt, ainda, natureza não é qualquer referência positiva; ao contrário, é um espaço em que não há igualdade, que só pode ser estabelecida artificialmente, e em que o homem se encontra fragilizado, sem a proteção do artifício político. São inúmeras as passagens em que ela apresenta esta idéia, e têm mais destaque aquelas em que ela aponta que o totalitarismo está associado ao afastamento da pessoa artificial do homem, ou seja, somente quando o homem é, entre outras coisas, naturalizado, é que um domínio totalitário se torna possível ${ }^{1}$.

\footnotetext{
${ }^{1}$ Neste sentido, ver a passagem: "Os sobreviventes do campo de extermínio, os internados nos campos de concentração e de refugiados e até os relativamente afortunados apátridas puderam ver, mesmo sem os argumentos de Burke, que a nudez abstrata de serem unicamente humanos era o maior risco que corriam. Devido a ela eram considerados inferiores e, receosos de que podiam terminar sendo considerados animais, insistiam na sua nacionalidade, último vestígio da sua antiga cidadania, como o último laço remanescente e reconhecido que os ligaria à humanidade" (Arendt, 1990, p. 333).
} 
Outra diferenciação que poderia ser feita entre a concepção de natureza entre os dois autores é que, para Rousseau, a busca pelas referências naturais e pela crítica que estas podem oferecer a um determinado estado de coisas é traduzida na busca pelas experiências originárias, sem qualquer interferência artificial, como exaustivamente apontado em Emílio. Esta busca pela essência de cada experiência é o que dá profundidade nas relações do homem com o espaço físico e, mais tarde, na relação do homem com outros homens. A busca da essência de cada experiência é o que pode levar, na visão de Rousseau, a uma visão racional e universal do mundo e, portanto, da política.

Para Arendt, também a experiência deve ser buscada. A singularidade de cada experiência tem um efeito desconstrutivo de regras gerais, e a profundidade que a experiência confere à vida humana não se dá pela via da busca de qualquer essência ou referência da natureza, mas pela 184 memória dessa experiência. E essa memória se dá sempre na forma de fragmento e de particularidade. Nunca poderá levar a qualquer juízo ou visão universalizante a respeito do mundo.

Apesar destas diferenças, ambos os autores depositam bastante importância no caráter artificial da política. Arendt, como já dito aqui, entende a política como algo eminentemente artificial. Para Rousseau, também o artifício é necessário, para o que basta lembrar o título de sua principal obra. Rousseau aposta suas fichas numa convenção que possa constituir uma nova sociedade, desfazendo os efeitos deformadores da sociedade civil, constituída também por convenção. Ou seja, para Rousseau, é justamente porque a política se estabelece por convenções que ela pode ser modificada e reconstituída. Também acontece assim para Hannah Arendt. E para ambos os autores o direito tem importância, mas em caráter um tanto distinto. Na concepção da autora, o direito é algo pré-político, que deli- 
mita o espaço político, mas não prescreve a ação que ocorre neste espaço, enquanto para Rousseau o direito assume um papel importante na constituição do contrato social que ele propõe e também na atividade política que então se estabelece, através da importância que dá ao poder de legislar e, principalmente, através da noção de dever que paira sobre os cidadãos no corpo político a ser criado, tanto em sua forma abstrata tal como proposta em $O$ Contrato Social, como em sua forma concreta, propondo uma Constituição para a Polônia, quando, por exemplo, observa que os funcionários do governo devem o ser por dever, e não por profissão (Rousseau, 1982. p. 70). Esta noção de dever não parece estar presente na obra de Hannah Arendt. Para ela, qualquer previsão determinada por uma lei ou conjunto de leis pode impedir a espontaneidade da ação dos homens, e, portanto, torná-la previsível. Hannah Arendt não vê na racionalidade proporcionada pelo cálculo possibilitado pelas leis nenhum bem a ser preservado num espaço político. Ao contrário, este deve ser o espaço da espontaneidade - que para ela nada tem a ver com racionalidade, previsibilidade e cálculo - e só dela.

Em resumo, no contrato social de Rousseau, a racionalidade vem em favor da espontaneidade. No espaço político de Hannah Arendt, a razão destrói a mesma espontaneidade. Essa oposição de modos de ver da razão, que provavelmente é o que coloca os dois em terrenos diferentes na teoria política, está relacionada com outro tema de que trataremos mais tarde: a vontade.

\section{Ator e espectador}

As diferenças entre as críticas à representação política realizadas por Arendt e Rousseau podem ser identificadas no tratamento que ambos dão a um outro tema caro ao âmbito da ação política, que é a relação entre o ator (ou agente) da ação política e o espectador dessa mesma ação. Se admi- 
tirmos que representação significa também "aparecimento" como o fizemos na primeira seção, é necessário analisar qual é a relação humana que se estabelece no "aparecimento" de alguém no mundo político.

É bastante conhecida a importância dada por Hannah Arendt ao espectador dos acontecimentos políticos, o que ela faz inspirada em sua leitura um tanto singular da Crítica do Juízo de Kant. Para ela, a ação desinteressada que todo ator intenta no espaço político somente pode ser vista e narrada de forma imparcial pelo espectador, que não está diretamente envolvido na ação. Isto porque o ator, por mais desinteressado e espontâneo que seja em sua ação, sempre faz parte do ato, e, portanto, não pode vê-lo e, mais importante, julgá-lo com real imparcialidade. O espectador, ao contrário do ator, pode se investir de um senso comum, que torna possível a ele pensar no lugar de outros e, assim, emitir um juízo que não represente somente o seu modo de ver, mas tenha uma expectativa de validade universal. Ou seja, embora o juízo de espectador seja, de fato, individual, com este senso comum seu juízo pode ser emitido como se-e este como se é importante - fosse um juízo coletivo. Este é o juízo político por excelência, que somente pode ser emitido pelo espectador, nunca pelo ator.

Para Hannah Arendt, como se vê, ator e espectador estão em locais diferentes e têm posições distintas num mesmo acontecimento político. É o ator, claro, que realiza a ação política, atividade humana por excelência, que é marcada pela espontaneidade. Esta ação,como Arendt define com clareza em sua obra, é marcada pela pluralidade. Esta pluralidade, a autora não diz, mas poderia ter dito, somente se evidencia quando o espectador assiste às diversas ações e pode verificar a singularidade de cada uma delas e a multiplicidade de todas elas. Esta distinção feita por Arendt entre ator e espectador somente é possível porque ela vê o espaço político como aquele em que os atores "aparecem" em público. 
Nesta representação, há espectadores que têm, por meio de seu senso comum, a capacidade de emitir juízos políticos.

Na obra de Rousseau, a relação entre ator e espectador se dá, mais uma vez, de forma um pouco diferente. Embora para ele haja também uma possibilidade de o sujeito sair de si por meio da imaginação, isto não é feito na condição de espectador. Para ele, esta transcendência de si mesmo possibilitada àquele que age politicamente se dá pela pitié, que proporciona que ele abandone o amor próprio e desenvolva o amor-de-si, que é justamente o sentimento que permite apreciar e desejar a vida em comunidade com os demais, sem qualquer mediação do interesse (Salinas Fortes, 1997, p. 62) ${ }^{2}$. Ainda que esta capacidade de sair de si do sujeito rousseauniano seja semelhante à do espectador arendtiano, há uma diferença fundamental. Para Rousseau, numa comunidade política soberana, com todos fazendo parte do corpo político e exercendo sem intermediários o poder de legislar, ator e espectador coincidem. Nem poderia ser diferente. Se há uma comunidade soberana, não há o "aparecimento" de uns para os outros. Todos fazem parte do soberano e todos participam da ação. Isso é possível por meio de sua formulação de vontade geral, que "funde os diversos grupos da sociedade republicana numa única essência, tornando cada homem ao mesmo tempo ator e espectador" (Freitas, 2003, p. 43). Não é por outra razão que as festas populares são, para nosso autor, uma metáfora da unidade da comunidade soberana:

“A festa exprime no plano 'existencial' da afetividade tudo aquilo que o Contrato formula no plano da teoria do direito.

\footnotetext{
2 É conveniente trazer aqui a formulação de Salinas Fortes: "Essa capacidade de identificação é a condição indispensável para que se constitua um vínculo efetivo, para além daquele formado com base no mero interesse: para que o homem deixe de gerar apenas em torno de si, é necessário que ele tenha, nele mesmo, a capacidade de 'sair de si', como se fora outro" (Salinas Fortes, 1997).
} 
Na embriaguez da alegria pública, cada um é ao mesmo tempo ator e espectador, reconhece-se facilmente a dupla condição de cidadão depois da conclusão do contrato - ele é a uma só vez 'membro do soberano' e 'membro do Estado', é aquele que quer a lei e aquele que obedece à lei. Fazei com que cada um se veja e se ame nos outros, a fim de que com isso todos estejam mais bem unidos. Olhar todos os seus irmãos, e ser olhado por todos: não é difícil redescobrir aqui o postulado de uma alienação simultânea de todas as vontades, em que cada um acaba por receber em troca tudo aquilo que cedeu à coletividade" (Starobinski, 1991, p. 107).

Nas festas, todos agem espontaneamente, de forma desinteressada, em conjunto, sem que uns "apareçam" para outros, ou busquem qualquer tipo de reconhecimento. Todos são atores e espectadores talvez porque ninguém seja, de fato, ator ou espectador. Estão apenas compartilhando espaço e circunstâncias comuns.

Aqui é necessário fazer uma observação. A beleza com que Rousseau descreve as festas populares que seus comentadores apontam e exploram positivamente é muito semelhante àquela com que Arendt descreve a formação e a atividade dos conselhos presentes em diversas situações revolucionárias presentes na experiência política do século XX, já citada aqui e também apontada positivamente por seus comentadores. Mas por que são tão diferentes? Como bem identificado na citação acima, para Rousseau, nas festas populares, metáfora de uma comunidade política soberana, o que a espontaneidade e a autenticidade possibilitam é a união dessa mesma comunidade. Nos conselhos arendtianos, a espontaneidade de sua formação e de suas decisões são demonstrações da pluralidade que marca o espaço político.

A separação entre ator e espectador efetuada por Arendt e a unidade entre estes idealizada por Rousseau abrem nossa reflexão para duas idéias que podem ser consideradas funda- 
mentais na diferenciação de suas respectivas teorias políticas e, por isso mesmo, do tratamento que cada um dá ao tema da representação política. Estas idéias são a pluralidade, que é a condição humana que marca a ação política, segundo Hannah Arendt, e a unidade, que caracteriza as comunidades políticas, segundo Rousseau. Elas, por sua vez, guardam relação estreita com outro tema caro à política e aos nossos dois teóricos: a vontade.

\section{Vontade, unidade e pluralidade}

Inicio esta seção com duas pendências: a oposição de tratamento dado à razão por Arendt e Rousseau e como pluralidade e unidade podem emergir na obra de cada um desses autores. Sem querer esgotar estes temas, mas sim indicar uma possível leitura, começo abordando a vontade.

Como é bem explicitado em várias obras de Hannah Arendt, tendo sido objeto específico de um ensaio, para ela ação política e vontade não estão relacionadas ${ }^{3}$. Destaco aqui que a vontade é afastada da política por Hannah Arendt por ela estar associada com prescrição e determinação futura de ações. Isto, como fica claro na obra de nossa autora, é incompatível com a idéia de espontaneidade e com a imprevisibilidade que são características essenciais da ação política tal como formulada por ela. A ausência da vontade na política arendtiana permite (ou condena) a autora a ter uma concepção fraca de lei e afastar lei e vontade do conceito de poder.

Embora a vontade seja objeto de um ensaio específico, é em $D a$ revolução que ela estabelece um diálogo em oposição aos conceitos de vontade geral e de soberania formulados por Rousseau. Como já dito aqui, a vontade geral está relacionada com a própria legitimidade da comunidade

\footnotetext{
${ }^{3}$ Trabalho esta questão em outro texto meu, com mais detalhe e aprofundamento (Abreu, 2004).
} 
política que se instaura com o contrato social. A vontade, ao lado do próprio contrato, é um elemento de racionalidade, que permite ao mesmo tempo a previsibilidade e o cálculo das ações futuras e também a legitimação desses atos futuros. Isto é possível porque a vontade geral expressa uma vontade comum que não se confunde com a vontade particular movida pelos interesses individuais e particulares. É uma vontade coletiva, de todo o corpo soberano, manifestada sem a mediação dos interesses. Ora, se Hannah Arendt concorda com o afastamento do interesse, não concorda com o restante da formulação de Rousseau. Para ela, inserir na política o cálculo e a previsibilidade é ameaçar a espontaneidade da ação. E a legitimidade da ação espontânea se dá pelo próprio ato coletivo que a gerou, ou seja, é absolutamente contingencial, sem ter relação com qualquer regra precedente. Para Arendt, a política é uma experiência que se legitima em sua própria origem, com a espontaneidade

190 e imprevisibilidade do ato que a gerou. Ou seja, para nossa autora, se há alguma relação entre racionalidade e legitimidade, o que não é explicitado em sua obra, ela se dá de forma muito diferente da formulada por Rousseau.

Em Rousseau, a racionalidade é o que pode dar à espontaneidade uma unidade. Dizendo em outras palavras, a racionalidade presente no estabelecimento de um contrato social e na manifestação da vontade geral é o que torna possível prever e fazer realizar, nas comunidades políticas, a unidade das diversas formas espontâneas de manifestação política. Tento tornar mais claro: imaginemos novamente a festa popular, em que todos estão compartilhando espaço e circunstância e compõem uma unidade. Isto se forma espontaneamente, sem qualquer determinação ou previsão. Ora, a existência de um contrato social que tem como exigência que a vontade geral se manifeste no exercício do poder legislativo é uma forma de tornar essa unidade previsível e, mais do que isso, fazê-la acontecer. Do contrário, teríamos que contar apenas 
com o acaso para que espontaneidade e unidade ocorressem simultaneamente. É neste sentido que ele propõe, abstratamente, um contrato social, que institua o dever e garanta a soberania de todos e, concretamente, a constituição da Polônia, com restrições a todos os mecanismos de falseamento das relações sociais concretas e estímulo às formas espontâneas de manifestação, como as festas populares.

Para Arendt, unidade não é algo a ser buscado. Ao contrário, muitas vezes tratando unidade como sinônimo de homogeneidade, é algo a ser combatido, pois, entre outras coisas, a homogeneidade era uma das características atribuídas ao povo pelos governos totalitários. Para ela, ao invés disso, o conjunto de pessoas que formam uma comunidade política - povo - devia ser vista como uma pluralidade de pessoas, cada uma com suas diversas capacidades de manifestação, inclusive política. É neste sentido que ela enaltece a concepção de governo dos founding fathers norte-americanos, especialmente de James Madison: "Segundo ele, partido e facção correspondem, no governo, às múltiplas vozes e diferenças de opinião que devem continuar existindo 'enquanto a razão do homem permanecer falível, e ele tenha liberdade de exercitá-la”" (Arendt, 1988, p. 74). E é neste sentido também que ela defende e incorpora a concepção de povo presente nos Artigos federalistas ${ }^{4}$. Como bem destacado em sua obra, e já afirmado aqui, a pluralidade é a própria condição da política. Para que essa pluralidade seja permanentemente possível, é necessário que nada esteja prescrito, determinado ou calculado.

\footnotetext{
4 "A palavra povo reteve para eles o sentido de coletividade, de infindável variedade de uma multidão cuja majestade residia em sua própria pluralidade. Oposição à opinião pública, ou seja, à unanimidade potencial de todos, era, por conseguinte, uma das muitas coisas sobre as quais os homens da Revolução Americana estavam plenamente de acordo; eles sabiam que o plano político, numa república, se constituía numa troca de opiniões entre iguais, e que esse plano simplesmente desapareceria, no próprio instante em que esse intercâmbio se tornasse supérfluo, se por acaso todos os iguais fossem da mesma opinião" (Arendt, 1988, p. 74).
} 
Se pudéssemos reduzir tudo isso em poucos termos, para Rousseau, a espontaneidade com adição de racionalidade resulta em unidade. Para Arendt, é necessário que não haja racionalidade, pelo menos não aquela formulada por Rousseau, para que se realize a pluralidade.

A isto devemos acrescentar que, para haver espontaneidade, para Rousseau, como já dito, não deve haver nenhum tipo de mediação entre o ator e sua ação, nem entre ator e espectador. A idéia de unidade, no mundo político rousseauniano, é, portanto, incompatível com a idéia de representação. Para Arendt, que não postula pela unidade, mas pela pluralidade, é da mediação entre o ator e sua ação - a ação é sempre apresentada - e entre ator espectador, que se obtém a pluralidade, que se realiza na diversidade de possibilidades de ação de um ator, que age sem nenhuma determinação ou prescrição, e da multiplicidade de interpretações e julgamentos possíveis de serem efetuados pelos espectadores.

\section{De volta à representação}

Temos de lembrar que, do ponto de vista político, a principal crítica de Rousseau à representação se dá no interior de sua defesa da unidade do corpo soberano. Neste sentido, para ele a representação deve estar ausente para que possa estar presente a unidade da comunidade política. Se levarmos isso para outras esferas além do contrato social, temos também que a representação impede que a autenticidade e a espontaneidade apareçam e possibilitem a unidade da comunidade social (Freitas, 2003, pp. 21-22). Com isso, a representação, nos dois sentidos, tanto de mandato político quanto de "aparecimento em público" são obstáculos para a unidade social e política.

Hannah Arendt, quando critica a representação política como delegação de poderes a representantes, parece ter como alvo principal o sistema representativo partidário, que traz para dentro da política o interesse e, portanto, 
retira dela a espontaneidade. Quanto à representação no sentido de "aparecimento" em público, esta é necessária, justamente porque aí os atores políticos, que já se tornaram iguais pela existência de leis que delimitam o espaço político, podem se singularizar e se distinguir em público. Isto possibilita a manifestação da pluralidade que Arendt coloca como marca distintiva da ação política. Para ela, espontaneidade e autenticidade não estão relacionadas. Ao contrário, como já dito, é necessário para a política que ela não seja o espaço da autenticidade. A representação é uma espécie de "máscara" protetora dos atores políticos.

Em relação mais especificamente à representação como delegação/mandato, as críticas aqui brevemente abordadas têm fundamentos distintos. Rousseau defende a espontaneidade e a transparência, às quais a representação política seria um obstáculo. Com isso, a unidade necessária para a formação de uma comunidade política soberana e capaz de agir conforme o bem comum seria inviável. Hannah Arendt defende também a espontaneidade, mas sem postular pela transparência. Ao contrário, é garantindo que cada um "apareça" e "represente" em público é que se viabiliza a pluralidade, característica do espaço político por ela proposto. Esta garantia necessária afasta a representação (delegação/mandato), pois com ela somente os interesses podem ser representados e se inviabiliza a manifestação das singularidades de cada um.

Como se vê, as duas críticas à representação têm fundamentos e alvos distintos. Na apropriação de qualquer uma dessas críticas, é necessário levar estes aspectos em consideração.

\section{Maria Aparecida Azevedo Abreu}

é mestre e doutoranda do Departamento de Ciência Política da Faculdade de Filosofia, Letras e Ciências Humanas da USP 


\section{Bibliografia}

ABREU, M. A. 2004. Hannah Arendt e os limites do novo. Rio de Janeiro: Azougue Editorial.

ARENDT, H. 1981. A condição humana. Rio de Janeiro: Forense Universitária. 1988. Da revolução. São Paulo: Ática/Universidade de Brasília. 1990. As origens do totalitarismo. São Paulo: Companhia das

Letras.

1992. Entre o passado e o futuro. São Paulo: Perspectiva.

1994. Lições sobre a filosofia política de Kant. Org. R. Beiner. Rio de Janeiro: Relume-Dumará.

1996. Crises of the Republic. New York: Harcourt Brace \& Company.

2002. “Little Rock”. In: KNOTT, M. L. (org.). Tiempos presentes. Barcelona: Editorial Gedisa, pp. 91-112.

FREITAS, J. 2003. Política e festa popular em Rousseau: a recusa da representação. São Paulo: Humanitas.

MADISON, J.; HAMILTON, A.; JAY, J. 1993. Os artigos federalistas. Rio de Janeiro: Nova Fronteira.

MONTESQUIEU, B. de. 2000. O espirito das leis. São Paulo: Martins Fontes.

ROUSSEAU, J.-J. 1982. Considerações sobre o governo da Polônia e sua reforma projetada. São Paulo: Brasiliense.

1987a. Do contrato social. São Paulo: Nova Cultural (Coleção Os Pensadores).

1987b. Ensaio sobre a origem das línguas. São Paulo: Nova Cultural (Coleção Os Pensadores).

1995. Os devaneios do caminhante solitário. Brasília: Editora UnB. 2004. Emílio, ou da educação. São Paulo: Martins Fontes.

2005. Discurso sobre a origem e os fundamentos da desigualdade entre os homens. São Paulo: Martins Fontes.

2006. Julia ou a nova Heloísa. São Paulo: Hucitec.

SALINAS FORTES, L. R. 1997. Paradoxo do espetáculo: política e poética em Rousseau. São Paulo: Discurso Editorial.

STAROBINSKI, J. 1991. Jean-Jacques Rousseau: a transparência e o obstáculo. São Paulo: Companhia das Letras.

VIROLI, M. 1992. Jean-Jacques Rousseau and the "well-ordered society". Cambridge: Cambridge University Press. 


\section{REPRESENTAÇÃO EM ROUSSEAU E HANNAH ARENDT}

MARIA APARECIDA AZEVEDO ABREU

$\mathrm{O}$ artigo tem como objetivo comparar as concepções de representação formuladas por Rousseau e Hannah Arendt. Sempre considerados como críticos da representação política, cada um dos autores faz sua crítica baseada em argumentos bastante distintos. Esses argumentos serão comparados, seguindo a trilha dos conceitos de natureza, artifício, vontade, unidade e pluralidade.

Palavras-chave: Hannah Arendt; Rousseau; Representação; Unidade e pluralidade; Natureza e artifício.

\section{REPRESENTATION IN ROUSSEAU AND HANNAH ARENDT}

The aim of the article is to compare the concepts of representation formulated by Hannah Arendt and Rousseau. Although both authors are considered critics of political representation, each one does her/his criticism focused on very different arguments. Those arguments will be compared, following the path trailed by the concepts of nature, artifice, will, unity and plurality.

Keywords: Hannah Arendt; Rousseau; Representation; Unity and plurality; Nature and artifice. 